\title{
EIGHT SIGNIFICANT EVENTS IN THE 50 YEAR HISTORY OF COMPUTING
}

\author{
T. William Olle
}

T. William Olle Associates, England

E-mail: BillOlle@aol.com

Abstract: The history of computing is relatively short compared with that of any other area of human knowledge, be it science, engineering, medicine, law, or accounting. On the other hand, the development of the field has been meteoric and computing now occupies a position as a major employer of professional persons, a major facet of industry and a body of knowledge to be disseminated at educational institutions and used - hopefully as a benefit to mankind.

To have a broad perspective on the history of computing for the purposes of education, it is informative to review something like a fifty year period and to identify the really significant events which have paid a major role in developing computing technology as we see it and use it at the present time. This paper is inevitably subjective, but is based on the author's fifty year involvement on different levels and in different facets of computing. The number "eight" is chosen, albeit arbitrarily, as a appropriate number for a subject such as computing.

Key words: Computing; Significant Events; 50 years; Stored program; Ferrite core memory Higher level languages; Disc memory; IBMSystem/360; Data base management; Personal computers; Internet

\section{WHAT IS COMPUTING?}

The term "computing" is interpreted in this paper as referring to "the use of stored program computers". Some may see this as restrictive in that it does not cover the use of purpose built electromechanical and electronic computers that preceded the development of the stored program electronic 
computer in 1948. It does not cover the use of accounting machines which some may argue were "programmed" by setting the plug boards. One can even look further back in time and take into account the early use of Hollerith cards that were first used in the 1890s.

\section{EDUCATIONAL IMPLICATIONS}

Most fields of human knowledge, which have an everyday practical application, have a much longer history than that of computing. When students are taught about such fields, some exposure to the history of the field is almost mandatory. Significant examples are architecture and medicine. It is open to question whether the time spent on this teaching should be one hour or 50 hours. The aim of the teaching of any field should be to put the practical knowledge in the associated course into some kind of temporal context.

\section{CRITERIA FOR SIGNIFICANCE}

This paper identifies eight events deemed by the author to be significant. The reason for selecting "eight" is that eight is in itself a significant number in the essentially binary world of computing. Four would be too few and sixteen would be too many. Seven was popular in early days, for example when the seven wonders of the ancient world were defined.

The concept of significance is important here. A significant event is regarded basically one which had a major and enduring impact on the practice of computing. It changed the manner in which computers were used and the evidence of the change lasted for a considerable period. An event may possibly have taken time to be assimilated. It may possibly related to two or more similar pieces of work involving different people, taking place in different parts of the world, but collectively over a restricted period.

\section{EVENT 1: STORED PROGRAM COMPUTER}

Within this framework for significance, the first qualifying event was the first running of a stored program on a general purpose computer. Prior to this event, it had been possible to store data in a computer, but the programs which were to operate on that data were either built-in electro-mechanically 
or electronically, and defined to the computer using a plug board or by setting dials on the computer.

The first running of a stored program on an (albeit experimental) computer is widely recognized as having taken place at Manchester University in June 1948 [1]. A program was keyed into the computer to evaluate the highest factor of a number. The computer in question used cathode ray tube storage, widely known at the time as Williams tubes after their inventor the late F.C. Williams. The invention of Williams tubes is not in itself seen as a significant event because these were very rapidly superseded by ferrite cores.

The computer was no more than a prototype. To celebrate the $5 \mathbf{5 0}^{\text {th }}$ anniversary of this event, a working replica was built and is on display in the Manchester Museum of Science and Technology.

In 1949, a "complete" stored program computer known as the EDSAC was taken into use at Cambridge University to provide a computing service to the university.

\section{EVENT 2: FERRITE CORES FOR MAIN MEMORY}

The arrival of ferrite core storage in the mid 1950s is seen as the second significant event. significant event. This technology was soon widely adapted as fast storage for computers. It was recognized as more economical and more reliable than such alternatives as cathode ray tube storage (William's tubes) and mercury delay lines used in EDSAC.

Some of the earlier work on core memory was carried out at Harvard University in 1949 by An Wang [2], [3]. At nearby MIT, Jay Forrester, working on the Whirlwind project, decided to use ferrite cores rather than William's tubes. The latter were already known to be temperamental and unreliable. An Wang was not granted a patent on ferrite core memory until 1955 by which time it was in use in many places. IBM paid Wang millions of dollars to purchase the patent rights.

The availability and indeed the economics of ferrite cores were helped by the availability of cheap labour in the Far East for assembly. Another advantage of ferrite cores over its rivals was that it could retain its contents indefinitely without power.

Before leaving the subject of ferrite cores, it is important to note that the concept of two levels of storage - one fast, the other less so - is a very early and basic concept which is still totally prevalent today. Ferrite cores have been used for high speed memory, whereas cheaper alternatives such as 
magnetic tapes and subsequently rotating discs have been used for what used to be called "backing store".

\section{EVENT 3: HIGHER LEVEL LANGUAGES}

In the early days, programs had to be written using the same set of instructions as the computer itself used, commonly referred to as machine code. There was a gradual evolution from this way of writing programs [4].

The main stepping stone was a symbolic assembler language. This allowed the machines instructions to be replaced in a program by some kind of mnemonic name, such as ADD for an addition and DIV for divide. At the same time the requirement to refer to data by using the machine's own internal addressing system was replaced by a facility for identifying data in a program using more mathematical symbols such as $\mathrm{X}, \mathrm{Y}$ and Z.

It is important to note that during the 1950s and early 1960s, scientific applications and commercial (or business) applications were treated as very separate indeed. Different kinds of hardware and software were used. As a result of this schism, two separate sets of higher level languages were developed.

One the scientific side, Autocode was developed for the Ferranti Mark 1 at Manchester University by R.A. Brooker and first demonstrated in 1954. Because the Mark 1 had a magnetic drum as its backing store, it was not necessary for an Autocode programmer to bother about transferring data from one level of memory to the other [5].

FORTRAN (an abbreviation for Formula Translation) was developed at IBM between 1954 and 1957 by John W. Backus for the IBM 704 [6]. This machine used magnetic tape drives for backing storage which was a strong reason for including in FORTRAN, the statements for reading and writing data between the core store and a designated tape unit.

ALGOL (Algorithmic Language) was also developed during the 1950s and is the result of dedicated work by many people in many places. An early effort was the Michigan Algorithm Decoder later designated ALGOL 58. There was also an ALGOL 60 and an ALGOL 68 that were the focus for one of the earliest IFIP Working Groups, namely WG2.1 [7].

On the commercial side, there is also a long list of items of early work. One of the earliest is the legendary Grace Hopper's A-O compiler in 1952, followed by ARITH-MATIC (1954), MATH-MATIC and FLOW-MATIC (both 1955). These were all developed while she was at Remington Rand Univac.

The US Department of Defense (DoD) had a major hand in the development of commercial higher level languages. In 1958, DoD was a 
major force behind the formation of the organization known as CODASYL (Conference on Data Systems Languages). The initial aim of this organization was to specify a Common Business Language, which came to be known as COBOL [8].

One early aim of COBOL was simple. Any accountant should be able to read and write it. In fact, COBOL had a tremendous influence on what was at the time called Business Data Processing.

Higher Level Languages in general have had an enduring impact on computing, but it would be extremely difficult to point to any specific piece of work as the significant event.

\section{EVENT 4: IBM SYSTEM/360 RANGE OF COMPUTERS}

The fourth event was initiated by an announcement in April 1964 [9]. It lead to the bringing together of computers for scientific applications with computers for business or more broadly speaking administrative applications. It was some time before the first IBM System/360 computers were delivered. At that time IBM had about $85 \%$ of the overall market with the remaining $15 \%$ shared by seven other manufacturers. Hence, there were frequent references at the time to "IBM and the seven dwarfs."

Prior to this event, many larger corporations were finding it necessary to have both a scientific and a business machine, typically in different departments of the corporation. There could be overlap in peripheral functions such as card punching and printing.

In addition to the hardware, IBM also announced an operating system, namely OS/360 which could handle both kinds of computing. There was knock-on effect on the compilers used to compile previously disparate languages such as FORTRAN and COBOL. Both of these needed to handle input from card readers, output to a printer as well as input and output to magnetic tapes. The systems software previously tailored for the compiler was unified in a part of the operating system called the data management system.

\section{EVENT 5: DISCS AS LARGE SCALE MEMORY}

The fifth significant event was the development of discs as large scale memory. The assimilation of this technology took quite a long time. The first computer to include a disc drive was introduced by IBM in September 1956 
[10]. The computer was the IBM 305 RAMAC and the disc drive was called the "IBM 350 disk drive". It had a capacity of five million 7-bit characters (4.8 megabytes using contemporary jargon).

It is noted in passing that the concept of two levels of storage (also called memory) is one that has been part of computing since the early days and is still to be found in today's personal computers. Early computers used magnetic drums and magnetic tapes. Discs had the advantage over drums that they allowed more data storage in less physical space. They also had the advantage of what was somewhat misleadingly called "random access" based presumably on the IBM RAMAC designation. This terminology soon became more correctly "direct access".

Without examining the economic factors in detail, one can only assume that magnetic tapes survived as long as they did for economic reasons. As larger problems were tackled in both scientific and business computing, there was a need for retaining larger volumes of stored data in computerized form.

However, it was during the 1960s that discs began to find wide spread acceptance. One of the main problems was making effective use of the extra dimension over and above that provided by magnetic tape files and the associated sequential processing.

The Indexed Sequential Access Method (ISAM) soon emerged which made it possible to access a single record in a direct access storage device (typically a disc) other than by scanning through many records as would be necessary with a magnetic tape file. Either an index was maintained, as in ISAM, or else the physical address of the record to be accessed could be calculated from the value of its key item.

\section{EVENT 6: DATABASE MANAGEMENT}

The sixth significant event was the evolution of data base technology that itself was enabled by the availability of disc storage. With magnetic tape files it was necessary to scan sequentially through a tape to search for a piece of data. With a database stored on a disc, it became possible to jump from a piece of data in one location on the disc to a piece of data in another location. The early pioneering work on this was started in the early 1960 s by Charles Bachman working at General Electric, which at that time was a computer manufacturer. However, the acceptance of this technology took at least a decade and was a major discussion point during the seventies.

Bachman was the first to recognize that discs provided an extra dimension to be exploited when storing and retrieving business records from high volumes of business data. He developed a software system as early as 
1963 called Integrated Data Store (IDS) which ran on the General Electric 225[11]. There was clearly a need to process the data stored in the records retrieved. At the time GE was using a language called GECOM as GE version of COBOL had not yet become available.

The future of IDS was strongly influenced by the industry wide acceptance of COBOL as developed by CODASYL. In 1964, US Steel persuaded the CODASYL COBOL Language Committee to investigate the inclusion of the IDS concepts into COBOL. The group charged with this responsibility was initially called the List Processing Task Force but the name was changed in May 1967 to Data Base Task Group (DBTG) [12].

The DBTG specifications were widely implemented around the world by manufacturers of the time but never by the world's dominant manufacturer, namely IBM. IBM adopted its own approach called Information Management System (IMS) in 1967.

In 1970, an IBM employee, the late Edgar H. Codd, published a seminal paper [13] on what came to be recognized as the relational model, not to be confused with the DBTG's network model and IMS's hierarchical model. The seventies proved to be a decade of intense debate over the relative merits of these three models. The debate took place in academia and among practitioners who recognized the importance of making the right decision on how to structure and maintain their employers' all important databases. The relational model is the one which has endured and it is the basis for the ISO SQL standard that all current commercially available database management products claim some kind of conformance.

\section{EVENT 7: PERSONAL COMPUTERS}

The seventh event also took place over several years [14]. It started as early as 1975 with the availability of kits from which "do it yourself enthusiasts could build a small personal computer for their own use. There were many significant developments between 1976 and 1981 by companies such as Apple, Commodore, Sinclair and Osborne.

However, it was in August 1981 that IBM introduced the IBM PC. It had a 16 bit CPU (based on an Intel 8088 chip), 16 kilobytes of RAM and two floppy drives. It came with an operating system known as MS-DOS which its implementer, Microsoft, persuaded IBM should not be an IBM exclusive. Ultimately, this had a significant effect on IBM's influence on the burgeoning personal computer industry.

The personal computer brought computing out of the office and research centre into the home and did more than any other event of the eight cited here to increase awareness of computing. 


\section{EVENT 8: INTERNET}

Finally, the eighth event is the development of the Internet [15]. The ability for computers to exchange data across dedicated data links had been possible for some time, but the availability of personal computers, coupled with the dramatic reduction in the cost of telecommunications capacity meant that it was technically possible for two individuals on different sides of the world to communicate with each other by electronic mail.

\section{CONCLUSIONS}

The selection of what the author considers to be the eight most significant events in the history of computing is inevitably subjective and surely controversial.

It must be emphasized that the sequence in which the events are presented in this paper is "quasi-temporal". One could possibly argue for exchanging the order of events 4 and 5. The omissions of the evolution of operating systems and of silicon chips are felt to be the major omissions.

It is interesting to summarize the breakdown of the eight events listed into hardware, software and both.

Stored program computer hardware and software

Ferrite core memories hardware

Higher level languages software

IBM360 range hardware and software

Discs hardware

Data base management software

Personal computers hardware and software

Internet hardware and software

The term "hardware" with respect to the Internet must include communications hardware.

It is hope that this necessarily brief overview of the history of computing will help stimulate the education of new practitioners into the subject as well as stimulating debate among them. 


\section{REFERENCES}

Author's note: There are many web references for most of the eight events described in this paper. Those that are cited here represent a modest selection. Each has proved valuable to the author in preparing this paper and are considered to be useful to any student who wishes to dig deeper.

[1] "The Manchester Small Scale Experimental Machine - The Baby" http://www.computer50.org/mark1/new.baby.html

[2] "Magnetic Core Memory - Wikipedia" http://en.wikipedia.org/wiki/Core_memory

[3] "History of Computing Industrial Era 1950 - 1951" http://www.thocp.net/timeline /1950.htm

[4] "Timeline of programming languages - Wikipedia" http://en.wikipedia.org/wiki /Timeline_of_programming_languages

[5] "The significance of Brooker's autocodes in taking early Manchester machines into the market (1954-1960)" www.computer50.org/mark1/gethomas /manchester_autocodes.html

[6] "Fortran - Wikipedia" http://en.wikipedia.org/wiki/Fortran

[7] "International Federation for Information Processing Working Group 2.1 ALGOL Bulletin 1959-1976" http://www.cbi.umn.edu/collections/inv/cbi00029.htmlf

[8] "COBOL History - Milestones"http://legacyj.com/cobol/cobol_history.html

[9] "Looking back - April 1964" http://www.beagle-ears.com/lars/engineer/comphist /ibm360.htm

[10] "IBM 305 RAMAC - the first computer with a hard disc drive in 1956" http://www.cedmagic.com/history/ibm-305-ramac.html

[11] "Web project on Charles W. Bachman" http://www.sis.pitt.edu/ mbsclass/ hall_of_fame/bachman.htm

[12] “CODASYL: historical background http://www.ee.und.ac.za/coursemain/DNE4DP2 /sqlnotes/CODASYL.htm

[13] "A relational model of data for large shared data banks" http://www.acm.orgclassics /nov95/toc.html

[14] "Personal Computer History" http://lowendpc.com/history/index.shtml

[15] Internet Society (ISOC) "All about the Internet: Brief history of the Internet" http:// www.isoc.org/internet/history/brief.shtml 